\title{
From Disability to Diversity: College Success for Students with Learning Disabilities, ADHD, and Autism Spectrum Disorder
}

\author{
Written by: Lynne C. Shea, Linda Hecker, and Adam L. Lalor
}

Published by: Columbia, SC: National Resource Center for The First-

Year Experience \& Students in Transition, 2019, 135 pages

Reviewed by: Cassandra Kepple, Graduate Assistant, Florida State University

From Disability to Diversity: College Success for Students with Learning Disabilities, ADHD, and Autism Spectrum Disorder (Lynne C. Shea, Linder Hecker, and Adam L. Lalor) seeks to de-emphasize earlier models of disability, encouraging faculty and staff in higher education to focus instead on the inclusion of learners with distinct needs. The book raises awareness of how learning differences shape college transition and success and shows faculty and staff how to advocate for students with learning differences. The primary emphasis is on creating inclusive learning environments at all levels. The book provides concise yet comprehensive coverage of three broad classes of learning differences, making it a valuable resource for faculty and staff, whatever their previous experience working with students with learning differences. In this review, I provide an overview of the book's organization and content before turning to its relevance for orientation, transition, and retention (OTR) professionals.

\section{Overview}

Shea and her colleagues open the book by describing the postsecondary context for students with a learning disability (e.g., dyslexia and dyscalculia), attention-deficit/hyperactivity disorder (ADHD), or autism spectrum disorder (ASD). The discussion is grounded in the various models surrounding disability, including the medical and legal models. In describing the legal model, the authors highlight specific obstacles 
in the transition from high school to college. For example, students with diagnosed learning disabilities often receive federally mandated accommodations in K-12 through a 504 plan, but 504 plans do not exist in the college setting. As such, the support students received in high school may just disappear at college entry. The Americans with Disabilities Act provides guidance and mandates for accommodations at the postsecondary level. Still, students must advocate for themselves and seek out the help of their institution's accessibility office.

The second chapter describes how learning disabilities, ADHD, and ASD may present in college students and how professionals can spot symptoms affecting students' college experiences. In addition, the authors seek to reframe learning disabilities, ADHD, and ASD as learning differences (LD), advocating for a more inclusive approach to accommodations at the college level.

Moving forward, the authors speak to how disruptive the transition to college can be for students with LD and provide strategies staff can use to make this tumultuous time go more smoothly for these students. Shea and colleagues draw attention to transitions beyond the first college year for which students with LD may need support. These include socializing with peers, the increasing difficulty of classes, campus involvement, and preparing for the job market.

Chapters 4 and 5 focus on supporting students within the classroom and in the cocurricular and extracurricular spaces on campus. Chapter 5, which describes out-of-classroom experiences, may be of most interest to OTR professionals. The authors recognize that the symptoms of various LDs can affect multiple aspects of a student's life and provide guidance to faculty and staff on how to support this population in housing, athletics, student organizations, and career planning, among other areas. Like any other student, students with LDs need to learn strategies for navigating health and wellness and decision-making in the less structured college environment. Still, it is important to acknowledge how the symptoms of various LDs may impact those areas of a student's life differently than other students. For example, Shea and her colleagues include a discussion of managing the discipline process, especially Title IX violations, for students with LDs that will be of particular interest to student affairs professionals.

Chapters 4 and 5 also provide guidance to faculty and administrators 
for helping students navigate cocurricular experiences, such as research and internships, and campus activities, such as athletics and student leadership. These experiences often require students to maintain complex schedules, work in group settings, finish projects on a timeline, and present their work to others. LDs can increase the difficulty of these tasks for some students. If faculty and staff know that students with LDs are participating in these experiences, they can work to support them by extending time on assignments, providing clear expectations and feedback, and using universal design (UD) to create a more inclusive environment (Shea et al., 2019).

In their conclusion, the authors provide specific recommendations to faculty and staff on how to best support students with LD. In addition, they discuss strategies for making the campus climate more supportive for students with disabilities, providing professional development opportunities, using UD principles across campus, and providing resources to various organizations that work with students with LD.

\section{Connections to Staff Involved with Orientation, Transition, and Retention}

Shea and her colleagues have written a guide meant to aid faculty and staff in providing students with learning differences the best possible experience they can have in college. As previously mentioned, the book addresses the transition experiences of students with learning differences and how professionals can smooth the college entry experience. The authors speak directly to ways orientation staff can make their programming more beneficial to students who may need accommodations. Not all students with LDs enter the institution knowing they have an LD or willing to self-identify. As such, transition staff must provide information about how institutions support students with LD from students' earliest contacts with the institution. The authors suggest that services for students with disabilities be addressed in general orientation sessions. In addition, orientations should have a separate session for students with disabilities where more detailed information can be shared.

From Disability to Diversity also serves as an essential resource for retention staff at postsecondary institutions. The authors designed the book to first address the presence of students with learning differences on college campuses, then to describe transitions into college life within 
this context, and finally to highlight faculty and staff's role in supporting these students throughout their entire time in college. Relying on their experience working with students with LDs, the authors show that these students are just a part of the increasingly diverse student population in higher education. Making them feel welcome and supporting their learning endeavors just like any other student are keys to ensuring the persistence and success of this college population.

From Disability to Diversity offers a concise guide for faculty and staff who want to better serve students of diverse backgrounds and could serve as an instrumental handbook for OTR staff across all postsecondary settings. The authors provide information on learning differences and their symptoms while also showing that students with LDs participate in all parts of college life just like other students. They make a case for adopting a diversity model in supporting students' transitions, classroom-based learning experiences, and cocurricular involvement. Shea and her colleagues offer detailed insight into how faculty and staff can help students with LDs within and outside the classroom and across various college transitions. I would recommend this book for higher education professionals who would like to know more about supporting students of diverse backgrounds across various postsecondary settings. 